\title{
Analysis on Technical Efficiency and Influencing Factors of Agricultural Production in China Based on the Stochastic Frontier Analysis model
}

\author{
Huang Weiwei ${ }^{1, \mathrm{a}}, \mathrm{Xu}$ Liwenjun ${ }^{1, \mathrm{~b}}$, Guo Yinru ${ }^{1, \mathrm{c}}$ \\ ${ }^{1}$ School of Humanities and Social Sciences Beijing Institute of Technology, Beijing, China
}

\begin{abstract}
This paper selects the panel data on 31 provinces (cities) in China, from 2007 to 2017, and uses Stochastic Frontier Analysis Model to measure the efficiency of technical efficiency and influencing factors of agricultural production in China. The research shows that from 2007 to 2017, China's agricultural average production technology efficiency has steadily improved, but there is still much room for development. The agricultural production technology efficiency is greatly different in different part of China. The eastern region has the highest efficiency, and the central and western regions are lower than the national average. Labor input, fertilizer application, and diesel fuel are factors that directly affect the technical efficiency of agricultural output. Time trend and urbanization level indirectly affect the agricultural production technology efficiency, and the impact is positive.
\end{abstract}

\section{Introduction}

With agriculture laying the foundation of human survival and development and keeping China's economic and social development stable, its important position is selfevident. 2020 is the decisive year to win the battle against poverty and build a well-off society in an all-round way. It is the year of the closing of the 13th Five-Year Plan. Carrying out the strategy of rural revitalization, paying attention to the development of the work of three rural issues, and filling up the weak links of three rural issues are of great significance for high quality to complete the target. And according to the recently released document No.1 of the 17th CPC Central Committee since the 21st century, which points out the work of three rural issues-Opinions of the CPC central committee and the state council on focusing on key work in agriculture, rural areas and farmers to ensure the timely realization of a well-off society in an all-round way, it also shows that the central government attaches great importance to the issue of agriculture, rural areas and farmers.

Since the 40 years of reform and opening up, China's agriculture and rural economic development have changed greatly, especially a series of agricultural reform policies, such as Household Contract Responsibility System, Purchase and Protection Price Policy of Agricultural Products, Reform of Rural Taxes and Fees, have liberated the rural productive forces, stimulated the enthusiasm of farmers, improved the efficiency of agricultural production, and promoted the overall development of rural areas. In addition, China's agricultural industrial structure has been constantly adjusted and optimized, from the grain-based farming economy to diversified management and comprehensive development of agriculture, forestry, animal husbandry and fishery, and the pace of agricultural reform has not stopped. But in recent years, China still has some shortcomings while carrying out the agricultural supply-side reform and achieving remarkable results. Among them, the problem of production efficiency in weak links of three rural issues cannot be ignored. At the present stage, although the efficiency of agricultural technology in China generally shows an upward trend, the agricultural extensive production mode has not been fundamentally changed, and there is also a big gap compared with the developed countries. Specifically, the development level of agricultural mechanization is not high, and the efficiency of production technology between regions is different, and the allocation efficiency of agricultural elements is on the low side.

Therefore, attaching importance to the improvement of the technical efficiency of agricultural production and making up for the shortcomings of the current agricultural production efficiency are the important guarantee to help overcome poverty and ensure the rural areas to build a well-off society in an all-round way. It is also the inherent requirements of speeding up the pace of agricultural modernization and promoting the strategy of rural revitalization.

\section{Literature review}

China's agricultural production technology efficiency and its influencing factors have been the key research object of agricultural development, and have been paid more and more attention by the theoretical circles. Total factor productivity (TFP) can be traced back to 1957 . Solow

ae-mail address: 18811230061@163.combe-mail address: Xu_liwenjun@163.com ce-mail address: 798828792@qq.com 
defined TFP to include all aspects of non-factor input factors, including both technological progress and institutional factors, as well as factor allocation factors [1].Since the reform and opening up in rural areas, scholars at home and abroad have carried out a lot of indepth research in different directions, and put forward many different conclusions. In the article published in 1989, Whalley suggested that the increase of agricultural product price and the increase of farmers' enthusiasm for production are the key to the improvement of agricultural production efficiency, but the influence caused by the system is not important [2]. During 1993, Wen made different opinions through data analysis from 1952 to 1989 that the Household Contract Responsibility System was the main reason for the improvement of agricultural production efficiency [3]. Entering the 21st century, Songqing Jin, Jikun Huang, Ruifa $\mathrm{Hu}$ and Scott Rozelle found that the existing literature of rural reform and opening up to now focused on the influence of institutional reform on agricultural production efficiency, overemphasized the effect of reform on the improvement of production efficiency and thus neglected other factors, and put forward that technological progress is the key to agricultural economic development [4].

Since 2005, with the end of the protection period of agricultural products after China's accession to the WTO, agricultural products have entered the international market, and the competition has become increasingly fierce. So relevant research on improving the efficiency of China's agricultural production has also increased. From the point of view of research, some scholars study the efficiency of agricultural technology in a certain area or compare different regions, such as Jiao Yuan[5];Han Zhenxing, Liu Donghui, Chang Xiangyang[6];Peng Daiyan, Wu Xiang[7];Wang Weihua[8]; some scholars study the overall technical efficiency level of domestic agriculture from the perspective of the whole, such as Yang Yiwu [9], Song Zengji [10], Chen Weiping [11]; some scholars study the techniques at different stages from the perspective of institutional or policy changes level of technical efficiency, such as Zheng Chunji [12]; some scholars analyze agricultural technical efficiency from the level of total factor productivity in agriculture, such as Wang Jun [13], Zhou Pengfei [14]. In terms of the research method, most of the literature uses quantitative analysis method: the typical Data Envelope Analysis method with nonparametric method, such as Wang Xiufeng [15], Hou Lin [16]; Stochastic Frontier Analysis Model of parameter method, such as Bai Ma Yongzhen [17]; regression analysis method, such as Zhang Yu [18].

To sum up, the domestic scholars' research on agricultural production efficiency and the introduction of models started later than those abroad, but the research on their calculations is relatively mature. They used different models to draw more accurate conclusions and impact factors. Their research on agricultural production efficiency focused on the relationship between agricultural economic growth, institutional changes, and agricultural production efficiency. Existing literature has provided a good guide for this study, but there are still some limitations. For example, in the previous literatures, when using the SFA model to measure efficiency, labor, land, mechanical power, and chemical fertilizers are often used as input factors, while ignoring the effects of pesticides and diesel fuel in agricultural production on measuring production efficiency. As we all know, with the transformation of agricultural modernization, the role of pesticides as the second largest production factor in addition to chemical fertilizers cannot be ignored, coupled with the continuous improvement of the degree of mechanization operations, as the main body of agricultural machinery energy consumption, its use is also increasing year by year. In addition, although some scholars have begun to pay attention to the impact of fiscal support for agriculture, planting structure and other elements, the actual situation of specific areas is not comprehensive enough. Moreover, most of the previous literature used time series data or cross-section data, compared with panel data, and the sample size of data was limited and not conducive to solving the problem of missing variables and improving the accuracy of estimation.

In view of the above problems, based on the existing literature, and based on the panel data with good timeliness from 2007 to 2017 at 31 provinces in China, this paper conducts an empirical study on the efficiency of agricultural technology in China and its influencing factors by using the Stochastic Frontier Analysis Model. The model can take the random error into account in the research and analysis for the characteristics of agricultural production caused by many uncontrollable factors, and make it more accurate and scientific. In addition, on the basis of selecting labor, land, mechanical power and chemical fertilizer as input elements, the two elements of pesticide and diesel fuel, which are easy to be ignored, can be added to make it more accurate to the current agricultural technical efficiency and the corresponding influencing factors in China, and analyze the overall situation of agricultural technical efficiency in China from a macro perspective.

\section{Empirical Analysis}

\subsection{Stochastic frontier Analysis model and Model building}

A basic principle of the Stochastic Frontier Analysis Model (SFA) is to introduce a nonnegative random variable based on the original regression model to measure the level of technical efficiency. Koopmas[19] and Debreu[20] first began the study of measuring the efficiency of decision-making units in 1951. During 1957, frontier analysis was applied to the analysis of unit efficiency of measurement by Farell. Through many experiments, he found that the results of frontier analysis in the process of studying unit efficiency coincide with various concepts of microeconomic theory such as production function, cost function, profit function. In 1977, Meeusen and van den Broeck [22] first established the Stochastic Frontier Analysis Model in the cross section data. After that, the SFA model has been developed rapidly, and also has been developed into one of the common methods of efficiency measurement. Battese and Coelli's model (BC1995), founded in 1995, first established the 
"one-step method" model in panel data [23]. This model operation is more flexible and accurate than the previous "two-step method ", which can estimate the influencing factors of efficiency and reduce the error caused by the correlation between input and efficiency. After 1995, as the SFA model has been gradually used skillfully, the effect of random factors on the production frontier efficiency can be fully taken into account by using SFA. Based on the research on the technical efficiency of agricultural production, this paper also analyzes its influencing factors, so the BC1995 model is selected. The model is constructed as follows:

$$
\begin{gathered}
\ln Y_{i t}=\beta_{0}+\beta_{1} T+\beta_{2} \ln L_{i t}+\beta_{3} \ln S_{i t}+\beta_{4} \ln M_{i t}+ \\
\beta_{5} \ln F_{i t}+\beta_{6} \ln D_{i t}+\beta_{7} \ln P_{i t}+v_{i t}-u_{i t} \\
T E_{i t}=\exp ^{\left(-u_{i t}\right)} \\
u_{i t}=\sigma_{0}+\sigma_{1} T+\sigma_{2} G+\sigma_{3} C+w_{i t}=z_{i t} \sigma+w_{i t} \\
\sigma^{2}=\sigma_{v}^{2}+\sigma_{u}^{2} ; \gamma=\frac{\sigma_{u}^{2}}{\sigma_{v}^{2}+\sigma_{u}^{2}} \\
\text { s.t }\left\{\begin{array}{l}
v_{i t} \sim \operatorname{iidN}\left(0, \sigma_{v}^{2}\right) \\
u_{i t} \sim i i d N\left(z_{i t}, \sigma_{u}^{2}\right) \\
w_{i t} \sim \operatorname{iidN}\left(0, \sigma_{u}^{2}\right) \\
i=1,2, \ldots, 31 \\
t=1,2, \ldots, 31
\end{array}\right.
\end{gathered}
$$

The equation (1) represents the SFA model, and the equation (2) represents the technical efficiency equation, and the equation (3) represents the technical inefficiency equation. $i$ indicates the region, and $t$ indicates the year, which begin in 2007 and finish in 2017, as the first year indicated 2007. Y, T, L, S, M, F, D, P represents the total agricultural output value, time trend item, labor input, land input, total power of agricultural machinery, fertilizer application, agricultural diesel fuel, pesticide application, respectively. $\mathrm{v}$ denotes random error. u denotes technical inefficiency effect. TE denotes production technical efficiency. w denotes random error of non-technical efficiency equation. $\mathrm{z}$ are the factors that affect technology inefficiency, including time $(\mathrm{T})$, fiscal support for agriculture $(\mathrm{G})$, urbanization $\operatorname{level}(\mathrm{C}) . \beta$ and $\delta$ are all parameters to be estimated. In the equation (4), $\gamma \in$ $[0,1], \gamma=0$; when $\sigma_{\mathrm{u}}^{2}=0$, it shows that the non-efficiency term does not exist, and the error is caused by random factors. The least square method can be used directly without the use of the random frontier model. When the $\gamma$ approaches 1, it indicates that the model error mainly comes from the technical inefficiency $\mathrm{u}$; and when the $\gamma$ approaches 0 , it indicates that the error mainly comes from random factors.

\subsection{Data description and indicator selection}

The time span of this paper is from 2007 to 2017. Panel data of 31 provinces (cities) are selected to analyze the technical efficiency of agricultural production in China. Data used in this study mainly come from the official website of the National Bureau of Statistics, the statistical yearbooks of various provinces and the China Rural Statistics Yearbook (2008-2018). The description and definition of the selected indicators are as follows:

Agricultural output: In this paper, the total agricultural output value (Y) of each province is selected as the output indicator. In order to eliminate the influence of price factors, the sales price index of rural commodities in each province is selected for deflation based on 2007. Because of the lack of data, rural commodity sales price index of Beijing, Tianjin, Shanghai and Chongqing are not counted, and the national average level is used instead.

Time trend (T): All the data in this paper are involved for a eleven-year period from 2007 to 2017.

Factor input: 1. Labor input(L): The number of agricultural employees can not be directly found from the National Bureau of statistics, so the number of primary industry employees, which shares the same trend with the number of agricultural employees, is selected as the labor input indicator. Since the data of Heilongjiang Province from 2011 to 2013 is missing, this study uses interpolation method to find out the proportion of employment in the three industries of the province (by using the data of employment in the three industries of Heilongjiang Province in 2011 and 2013 and the average speed), and finally multiplied by the total number of annual employees published by the province. 2.Capital investment: In the past, scholars usually used the total power of agricultural machinery (M) and the fertilizer application (F) as the main inputs of agricultural production when studying the technical efficiency of agricultural production. Based on this, agricultural diesel fuel(D) and pesticide application (P) are added in this paper.

Factors affecting technical inefficiency: 1. Time variable (T): From 2007 to 2017. 2. Fiscal support for agriculture $(G)$ : In order to eliminate the impact of scale factor, the proportion of fiscal expenditure on agriculture to local general public budget is used to represent the government support. Fiscal expenditures for agriculture support are expressed in terms of agricultural, forestry and water affairs expenditures, that is, agricultural expenditure items in the general budget of local finance, including agricultural expenditures, forestry expenditures, water conservancy expenditures, poverty alleviation expenditures, agricultural comprehensive development expenditures and so on. 3. Urbanization level (C): This indicator is expressed by the proportion of urban population to the permanent population at the end of the year.

\subsection{Results and analysis of the model}

This paper uses Front41.exe software to calculate the technical efficiency of agricultural production in each province (municipalities and autonomous regions) from 2007 to 2017 . The specific results are shown in table I. 
TABLE I Parameter estimation results of the Stochastic Frontier Production Model and the Inefficiency-Effects Function

\begin{tabular}{|c|c|c|c|c|c|}
\hline & Variables & Parameter & Coefficient & $\begin{array}{c}\text { Standard } \\
\text { error }\end{array}$ & T-ratio \\
\hline \multirow{8}{*}{$\begin{array}{c}\text { The } \\
\text { Stochastic } \\
\text { Frontier } \\
\text { Production } \\
\text { Model }\end{array}$} & Constant & $\beta_{0}$ & $1.9051 * * *$ & 0.1697 & 11.2229 \\
\hline & $\mathrm{T}$ & $\beta_{1}$ & -0.0105 & 0.0097 & -1.0811 \\
\hline & $\operatorname{lnL}$ & $\beta_{2}$ & $0.4518 * * *$ & 0.0815 & 5.5443 \\
\hline & $\ln S$ & $\beta_{3}$ & 0.059 & 0.0367 & 1.6097 \\
\hline & $\ln M$ & $\beta_{4}$ & 0.0111 & 0.0161 & 0.6926 \\
\hline & $\ln F$ & $\beta_{5}$ & $0.3657 * * *$ & 0.0085 & 43.2109 \\
\hline & $\ln \mathrm{D}$ & $\beta_{6}$ & $0.0925 * * *$ & 0.0121 & 7.6748 \\
\hline & $\ln \mathrm{P}$ & $\beta_{7}$ & 0.0342 & 0.0289 & 1.1843 \\
\hline \multirow{6}{*}{$\begin{array}{c}\text { The } \\
\text { Inefficiency- } \\
\text { Effects } \\
\text { Function }\end{array}$} & Constant & $\delta_{0}$ & $2.017 * * *$ & 0.0693 & 29.0919 \\
\hline & $\mathrm{T}$ & $\delta_{1}$ & $-0.0563 * * *$ & 0.0218 & -2.5869 \\
\hline & $\mathrm{G}$ & $\delta_{2}$ & -0.0051 & 0.032 & -1.5888 \\
\hline & $\mathrm{C}$ & $\delta_{3}$ & $-0.0016 * * *$ & 0.0028 & -5.7655 \\
\hline & \multicolumn{2}{|r|}{$\sigma^{2}$} & $0.0381 * * *$ & 0.0058 & 6.5772 \\
\hline & \multicolumn{2}{|r|}{$\gamma$} & $0.9983 * * *$ & 0.0132 & 75.7222 \\
\hline & \multicolumn{2}{|c|}{$\begin{array}{l}\log \text { likelihood } \\
\text { function }\end{array}$} & \multicolumn{3}{|c|}{89.45} \\
\hline & \multicolumn{2}{|c|}{$\begin{array}{l}\text { LR test of the one- } \\
\text { sided error }\end{array}$} & \multicolumn{3}{|c|}{97.07} \\
\hline
\end{tabular}

\subsubsection{The Stochastic Frontier Production Model}

According to the estimation results of the Stochastic Frontier Analysis Model in Table I, $\gamma=0.9983$, which is close to 1 , and this figure passes the significance test at the level of $1 \%$, indicating that the error term is mainly caused by non-technical efficiency, and the Stochastic Frontier Analysis Model used in this paper is applicable.

$\beta_{1}$ is negative and fails to pass the significance test, which indicates that the time factor do not directly have a significant effect on agricultural production during the inspection period. $\beta_{2}=0.45$, which is statistically significant at the $1 \%$ level of significance, indicating that as labor input increased by $1 \%$, agricultural output increased by 0.45 percentage points. The large marginal output of labor in agricultural production indicates that in actual production, China's agricultural production is essentially a labor-intensive industry and is still at a stage where labor force is dominant. Since China's agriculture is currently in and will be in the state of small-scale agricultural production for a long time, the increase in labor force is the easiest way to increase agricultural output at present. At the same time, it also shows that the total level of agricultural labor is at a relatively low stage where rural labor force is in shortage, according to the law of decreasing scale efficiency of labor. This is closely related to the inertia that young and middle-aged labor force entered urban employment in the first 30 years of reform and opening up in China. However, the trend is expected to be reversed with the construction of agriculture, rural areas and farmers in the future.

$\beta_{3}$ and $\beta_{4}$ are positive, but fail to pass the significance test, indicating that land input and total power of agricultural machinery do not have a significant effect on agricultural production. Land input and total power of agricultural machinery are important factor inputs in the process of agricultural production. Generally speaking, the two should have a significant positive impact on agricultural production, which means the larger the amount of input is, the higher the technical efficiency of agricultural production becomes, while the empirical results are not significant. In the central, western and southeastern regions of China, the soil fertility is low, and the black soil resources in the three northeastern provinces(Liaoning, Jilin, Heilongjiang) are rich and fertile. However, due to excessive exploitation and neglect of soil and water conservation for a long period, spring waterlogging regularly occurs in the northeast China, which leds to serious soil erosion. Moreover, during the period of large-scale development in history, some local cadres blindly pursued deep ploughing, ignored the scientific distribution of soil fertility and the regenerability of soil. As a result, the soil fertility was heavily consumed, resulting in the gradual decline of soil fertility.

$\beta_{5}=0.37$, which is significant at the level of $1 \%$, indicating that as the use of chemical fertilizer increases by $1 \%$, agricultural output increases by 0.37 percentage points. The analysis of $\beta_{3}$ and $\beta_{4}$ shows that the fertility of the land has decreased, while the input of fertilizer can directly increase the fertility of the land, thus directly increasing the output of agriculture. $\beta_{6}$ is equal to 0.0925 , passing the significance test at the level of $1 \%$, indicating that as agricultural diesel fuel increased by $1 \%$, agricultural production increases by 0.09 percentage points. Agricultural diesel fuel is mainly suitable for mechanical operations such as pumping, ridging, ditching and ploughing. The increase in input of agricultural diesel fuel and the improvement of agricultural production technology are conducive to the increase of agricultural output, so as to promote the technical efficiency of agricultural production.

$\beta_{7}$ is positive, but it fails to pass the significance test. There are two main reasons why pesticide application is not significant in agricultural production. One is that China is a large agricultural country with a long history, rich experience in agricultural planting, sufficient experience in pest control, and less pesticide application. In addition, China owns a fast-developing and relatively complete supermarket and agricultural trade procurement system, with strict detection of pesticide content in agricultural products. The other reason is that China's traditional mode of agricultural production has its own advantages. Nowadays many regions have implemented scale agriculture. For example, there is a few scale agriculture in the northeast and Henan Province - making full use of the advantages of the local Great Plains for agricultural production, but in terms of the entire ecological area, China's agriculture has maintained the diversity of crop species and objectively reduced the losses caused by a single pest to large-scale crop production. Moreover, the genetic diversity of the same species enhances the resistance of crops to pests, rather than the large-scale agriculture in the United States which requires a lot of pesticide input to protect against largescope pests that may come at any time.

In summary, during the inspection period, labor input, 
fertilizer application and agricultural diesel fuel have the greatest impact on agricultural production.

\subsubsection{The Inefficiency-Effects Function}

$\delta_{1}, \delta_{2}$ and $\delta_{3}$ are all negative, indicating that the temporal trend, fiscal support and urbanization level all change in the opposite direction to the technical non-efficiency, and positively to the technical efficiency of agricultural production. However, $\delta 2$ fails to pass the significance test at $10 \%$ level.

$\delta_{1}=-0.0563$, which passes the significance test at $1 \%$ level, showing that the inefficiency effect decreases over time, which indirectly affects the improvement of technical efficiency of agricultural production.

$\delta_{2}=-0.005$, which fails to pass the significance test at $10 \%$ level, indicating that the fiscal support do not have a significant impact on technical efficiency of agricultural production during the inspection period. On the one hand, a large amount of fiscal investment is used in the construction of agricultural infrastructure, which is called sunk cost with a long payback. Therefore, it is difficult to improve the technical efficiency of agricultural production in the current period. In terms of the content and structure, fiscal support prefers long-term investment, so actually only a small part of investment can be directly converted into production techniques that improve productivity, such as greenhouses. On the other hand, fiscal support for agriculture lacks supervision and designated objects, so local governments do not know how to properly use the funds allocated by the central and provincial governments. Some local governments either imitate the experience of advanced regions but ignore the local development level, or continue the previous construction without innovations. Inaccurate judgment and repeated investments lead to the waste of resources, which is difficult to have a significant impact on agricultural efficiency.

$\delta_{3}=-0.02$, which is significant at the level of $1 \%$, indicating that the urbanization level and the technical inefficiency effect change in the opposite direction. The high urbanization level is conducive to reducing the nonefficiency efficiency, thereby improving the technical efficiency of agricultural production. The reason may be the radiation effect of the city. The development of the central city is conducive to better promoting the adjustment of economic structure, playing a leading role in the development of agricultural production in the surrounding rural areas, enhancing the rural planting capacity and management capacity, so as to improve the efficiency of agricultural production and radiate the surrounding rural areas.

\subsubsection{Analysis of Technical Efficiency of Agricultural Production in China 2007-2017}

This paper uses Front41.exe software to get the estimated value of agricultural production technology efficiency of China's provincial regions. The result can be seen from the table II and table III.
TABLE II Estimates of agricultural technology efficiency in different provinces of China (2007-2017)

\begin{tabular}{ccccccc} 
& & & & & & \\
\cline { 2 - 6 } Province & $\mathbf{2 0 0 7}$ & $\mathbf{2 0 0 8}$ & $\mathbf{2 0 0 9}$ & $\mathbf{2 0 1 0}$ & $\mathbf{2 0 1 1}$ & $\mathbf{2 0 1 2}$ \\
\hline Beijing & 0.62 & 0.65 & 0.75 & 0.79 & 0.82 & 0.85 \\
Tianjing & 0.40 & 0.41 & 0.45 & 0.54 & 0.57 & 0.62 \\
Hebei & 0.31 & 0.32 & 0.36 & 0.45 & 0.44 & 0.47 \\
Shanxi & 0.23 & 0.26 & 0.31 & 0.35 & 0.37 & 0.39 \\
Inner & 0.33 & 0.34 & 0.34 & 0.40 & 0.45 & 0.48 \\
Mongoria & 0.39 & 0.40 & 0.39 & 0.45 & 0.49 & 0.56 \\
Liaoning & 0.31 & 0.33 & 0.33 & 0.34 & 0.36 & 0.39 \\
Jilin & 0.31 & 0.34 & 0.35 & 0.38 & 0.47 & 0.59 \\
Heilongjiang & 0.39 \\
Shanghai & 0.64 & 0.68 & 0.80 & 0.94 & 0.96 & 0.95 \\
Jiangsu & 0.37 & 0.41 & 0.48 & 0.55 & 0.62 & 0.70 \\
Zhejiang & 0.37 & 0.39 & 0.43 & 0.53 & 0.58 & 0.62 \\
Anhui & 0.22 & 0.24 & 0.26 & 0.30 & 0.31 & 0.34 \\
Fujian & 0.35 & 0.36 & 0.40 & 0.45 & 0.49 & 0.54 \\
Jiangxi & 0.28 & 0.30 & 0.31 & 0.34 & 0.37 & 0.41 \\
Shandong & 0.35 & 0.38 & 0.43 & 0.48 & 0.48 & 0.50 \\
Henan & 0.28 & 0.29 & 0.33 & 0.39 & 0.38 & 0.41 \\
Hubei & 0.26 & 0.28 & 0.30 & 0.37 & 0.41 & 0.44 \\
Hunan & 0.31 & 0.33 & 0.35 & 0.43 & 0.46 & 0.49 \\
Guangdong & 0.34 & 0.35 & 0.37 & 0.43 & 0.46 & 0.49 \\
Guangxi & 0.26 & 0.28 & 0.29 & 0.33 & 0.37 & 0.40 \\
Hainan & 0.35 & 0.38 & 0.43 & 0.45 & 0.49 & 0.56 \\
Chongqing & 0.28 & 0.30 & 0.34 & 0.39 & 0.44 & 0.48 \\
Sichuan & 0.29 & 0.34 & 0.39 & 0.44 & 0.50 & 0.56 \\
Guizhou & 0.21 & 0.24 & 0.26 & 0.31 & 0.31 & 0.39 \\
Yunnan & 0.21 & 0.22 & 0.23 & 0.23 & 0.26 & 0.31 \\
Tibet & 0.32 & 0.34 & 0.30 & 0.33 & 0.34 & 0.35 \\
Shaanxi & 0.27 & 0.31 & 0.31 & 0.39 & 0.46 & 0.49 \\
Gansu & 0.26 & 0.26 & 0.28 & 0.30 & 0.31 & 0.33 \\
Qinghai & 0.23 & 0.24 & 0.25 & 0.35 & 0.39 & 0.43 \\
Ningxia & 0.24 & 0.26 & 0.29 & 0.36 & 0.34 & 0.36 \\
Xinjiang & 0.49 & 0.44 & 0.49 & 0.68 & 0.62 & 0.67 \\
Average & 0.33 & 0.34 & 0.37 & 0.43 & 0.46 & 0.50 \\
\hline & & & & & &
\end{tabular}

TABLE II Connect to Table II

\begin{tabular}{ccccccc}
\hline Province & $\mathbf{2 0 1 3}$ & $\mathbf{2 0 1 4}$ & $\mathbf{2 0 1 5}$ & $\mathbf{2 0 1 6}$ & $\mathbf{2 0 1 7}$ & Average \\
\hline Beijing & 0.91 & 0.90 & 0.98 & 0.98 & 0.95 & 0.84 \\
Tianjing & 0.70 & 0.76 & 0.82 & 0.85 & 0.70 & 0.62 \\
Hebei & 0.51 & 0.49 & 0.49 & 0.50 & 0.52 & 0.44 \\
Shanxi & 0.41 & 0.43 & 0.43 & 0.42 & 0.45 & 0.37 \\
Inner & 0.52 & 0.52 & 0.53 & 0.52 & 0.51 & 0.45 \\
Mongoria & 0.58 & 0.60 & 0.70 & 0.63 & 0.64 & 0.53 \\
Liaoning & 0.53 & 0.41 & 0.42 & 0.36 & 0.35 & 0.36 \\
Jilin & 0.40 & 0.81 & 0.59 \\
Heilongjiang & 0.71 & 0.81 & 0.80 & 0.81 & 0.90 & 0.59 \\
Shanghai & 0.94 & 0.97 & 0.94 & 0.86 & 0.89 & 0.87 \\
Jiangsu & 0.75 & 0.82 & 0.93 & 0.95 & 0.99 & 0.69 \\
Zhejiang & 0.67 & 0.72 & 0.75 & 0.84 & 0.88 & 0.62 \\
Anhui & 0.37 & 0.39 & 0.41 & 0.43 & 0.46 & 0.34 \\
Fujian & 0.58 & 0.63 & 0.65 & 0.72 & 0.77 & 0.54 \\
Jiangxi & 0.44 & 0.47 & 0.55 & 0.59 & 0.63 & 0.43 \\
Shandong & 0.57 & 0.62 & 0.65 & 0.62 & 0.64 & 0.52 \\
Henan & 0.43 & 0.45 & 0.46 & 0.46 & 0.49 & 0.40 \\
Hubei & 0.47 & 0.50 & 0.53 & 0.57 & 0.63 & 0.43 \\
Hunan & 0.48 & 0.49 & 0.50 & 0.54 & 0.58 & 0.45 \\
Guangdong & 0.54 & 0.56 & 0.59 & 0.65 & 0.69 & 0.50 \\
Guangxi & 0.42 & 0.45 & 0.49 & 0.54 & 0.60 & 0.40 \\
Hainan & 0.59 & 0.65 & 0.72 & 0.82 & 0.85 & 0.57 \\
& & & & & &
\end{tabular}




\begin{tabular}{ccccccc} 
Chongqing & 0.51 & 0.55 & 0.60 & 0.73 & 0.77 & 0.49 \\
Sichuan & 0.59 & 0.64 & 0.70 & 0.78 & 0.87 & 0.55 \\
Guizhou & 0.45 & 0.59 & 0.79 & 0.85 & 0.98 & 0.49 \\
Yunnan & 0.35 & 0.38 & 0.39 & 0.40 & 0.43 & 0.31 \\
Tibet & 0.35 & 0.39 & 0.39 & 0.29 & 0.45 & 0.35 \\
Shaanxi & 0.54 & 0.60 & 0.61 & 0.65 & 0.68 & 0.48 \\
Gansu & 0.36 & 0.36 & 0.38 & 0.41 & 0.47 & 0.34 \\
Qinghai & 0.50 & 0.51 & 0.50 & 0.57 & 0.60 & 0.42 \\
Ningxia & 0.39 & 0.41 & 0.47 & 0.47 & 0.49 & 0.37 \\
Xinjiang & 0.68 & 0.68 & 0.69 & 0.72 & 0.76 & 0.63 \\
Average & 0.54 & 0.57 & 0.61 & 0.63 & 0.67 & - \\
\hline
\end{tabular}

TABLE III Estimates of agricultural technology efficiency in different regions of China (2007-2017)

\begin{tabular}{ccccccccccccc}
\hline Region & 2007 & 2008 & 2009 & 2010 & 2011 & 2012 & 2013 & 2014 & 2015 & 2016 & 2017 & Average \\
\hline East & 0.41 & 0.43 & 0.49 & 0.56 & 0.59 & 0.63 & 0.68 & 0.71 & 0.75 & 0.78 & 0.79 & 0.62 \\
Central & 0.26 & 0.28 & 0.31 & 0.36 & 0.38 & 0.41 & 0.43 & 0.46 & 0.48 & 0.50 & 0.54 & 0.40 \\
West & 0.28 & 0.30 & 0.31 & 0.38 & 0.40 & 0.44 & 0.47 & 0.51 & 0.55 & 0.58 & 0.63 & 0.44 \\
Northeast & 0.34 & 0.36 & 0.36 & 0.39 & 0.44 & 0.51 & 0.56 & 0.61 & 0.64 & 0.60 & 0.63 & 0.49 \\
\hline
\end{tabular}

From TableII and TableIII, the following analysis can be drawn:

(1) From 2007 to 2017, China's agricultural technical efficiency has steadily improved, from 0.32 in 2007 to 0.65 in 2017. And from 2011 to 2012, the data of agricultural technical efficiency increased most significantly, from 0.45 to 0.50 . The reason was that China's agricultural tax was completely abolished in 2006, and agricultural subsidies continue to increase, and fiscal support for agriculture had increased. 2011 is the last year of the "Eleventh Five-Year Plan". The Party Central Committee mentioned in the "2011 National Policies and Projects for Supporting Agriculture" that it is necessary to accelerate the construction of modern agriculture and new countryside and take new steps to create a good start for the Twelfth Five-Year Plan. Therefore, the government should increase fiscal investment in rural construction. It can be seen that the central government's policy of supporting agriculture and benefiting farmers has constantly improved our enthusiasm for agricultural production, and the technical efficiency of agricultural production has increased year by year. However, the table shows that the current technical efficiency of agriculture production is 0.65 , which still has a large distance from the production frontier. This shows that China's technical efficiency of agriculture production still has much room for improvement.

(2) The overall average technical efficiency of agriculture in the east of China is higher than the national average. In addition, the average annual agricultural technology efficiency in the eastern region is higher than the national average. Here is the reason: Firstly, in terms of natural conditions, good climate environment provides sufficient water for crops, and the terrain provides favorable conditions for agricultural modernization. Secondly, the speed of economic development in eastern region is fast, and the overall level of agricultural modernization is relatively high. Moreover, this the local finances are relatively solid, and the support is strong. It is worth mentioning that among the eastern regions, Beijing ranked first in the agricultural technical efficiency of the eastern region for 9 consecutive years, increasing from 0.62 in 2007 to 0.98 in 2016. In 2017, Beijing's agricultural technology dropped to 0.95 , and Jiangsu Province surpassed Beijing with its agricultural technology efficiency reaching 0.99 , occupying the first place in the eastern region. On the contrary, in the eastern region, Hebei Province had the lowest agricultural technical efficiency and the slowest growth, with 0.31 in 2006 and 0.52 in 2017 . Its 10 -year average is only 0.44 , significantly lower than other regions. In terms of the natural environment, in recent years, the soil salinization in Hebei has intensified, and the spring drought and summer waterlogging are not conducive to agricultural technology development. This is also related to the overall economic development status and structure of Hebei Province. Hebei Province surrounds Beijing and Tianjin, with limited local finances and slower economic growth than other eastern provinces. Its leading industries are information industry and high-tech industry, and its competitive industries are metallurgy, chemical industry, machinery, textile, etc. The agricultural development in Hubei Province is backward.

(3) The overall average technical efficiency of agriculture in the Northeast of China is the same as the national level. However, the estimated value of agricultural technical efficiency in the Northeast region was higher than the national level before 2015, and then became lower than the national average in 2015,2016 and 2017. This gap is still widening. Taking 2015 as the cutoff point, the high efficiency of agricultural technology in the northeast region in the early period was mainly due to its good soil conditions, which was a key area for agricultural development, and the agricultural development in the northeast region had a long history and a good foundation. Among the three provinces in the Northeast region, Heilongjiang Province's agricultural technical efficiency has the fastest growth. During the survey period, except for the slight declined in 2015, the remaining years have maintained rapid growth. The data of Liaoning Province and Jilin Province both declined sharply in 2016, which are two of the few areas with negative growth in agricultural technical efficiency. The main reasons are the following: Firstly, there is a serious shortage of cultivated land resources in Liaoning and Jilin Province and the amount of low yield fields are large. Secondly, the contradiction between the allocation of water resources and the allocation of land resources cause a shortage of water resource. Thirdly, Liaoning 's agricultural business model is traditional and can not meet the needs of modern agricultural development. The concrete manifestation is that the land circulation area accounted for $25.6 \%$ of the total area of household contracted arable land, which was 7.7 percentage points lower than the national average.

(4) Since the Western Development Strategy and the strategy for the rise of central region, the government has continuously strengthened its support for the central and 
western regions. Although the efficiency of agricultural production technology in the central and western regions has been greatly improved, there is still a large gap from the national average. The table III shows that the efficiency of agricultural technology in China's central and western regions was lower than the national average, from 2007 to 2017. This situation may be caused by the geographical environment of the central and western regions. The central and western regions are located in the inland areas of China, far away from the ocean. Compared with the eastern coastal areas, precipitation is relatively scarce. Many provinces such as Shanxi, Anhui, and Inner Mongolia are water-scarce provinces. In addition, the complex and mountainous terrain in the central and western regions is not conducive to agricultural cultivation. For example, brown soil in Inner Mongolia, black loessial soil in parts of Shaanxi, Ningxia, Gansu, and laterite in Yunnan are all soils that are less fertile and are not conducive to agricultural cultivation. The overall agricultural technology efficiency of Guizhou, Chongqing, Sichuan, Xinjiang and Shanxi provinces is relatively high and higher than the average of the western region. Among the five provinces, Guizhou's agricultural technical efficiency has the fastest improvement rate, from 0.21 in 2007 to 0.98 in 2017, ranking first in the western region. However, Yunnan Province is at the bottom of agricultural technology efficiency in the western region. The terrain of Yunnan Province is complicated and the altitude difference is large, which has greatly restricted the increase of agricultural technical efficiency. In the central region, the estimates of agricultural efficiency among provinces are relatively close.

\section{Analysis conclusion}

This paper selects the panel data on 31 provinces (cities) in China, from 2007 to 2017. The SFA model is used to measure the efficiency of Chinese agricultural production technology and its influencing factors. According to the above empirical analysis, the following conclusions are drawn:

In the stochastic frontier model, the labor force, chemical fertilizer and agricultural diesel have significant influence on the improvement of agricultural production technology efficiency, which indicates that the increase of these three inputs is beneficial to the improvement of agricultural production technology efficiency in China.

In the non-efficiency equation, the time trend term and urbanization level have a significant negative effect on the non-efficiency. This indicates that with the passage of time and the improvement of urbanization level, the inefficient effect is reduced, which indirectly affects the improvement of agricultural production technology efficiency level.

The analysis of efficiency values shows that the average agricultural production technology efficiency in China has steadily improved, but the overall agricultural production technology efficiency is still at a lower level, with great potential for development. The eastern region has the highest agricultural production technology efficiency, which is far higher than the national average.
The northeast region has a higher agricultural production technology efficiency, which is equal to the national average, but has a downward trend after 2015. The technical efficiency of agricultural production in the central and western regions has been continuously improved, but it is still below the national average.

\section{Acknowledgment}

First of all, we sincerely thank Professor Song Xianping. This article was completed under the guidance of her.

She gave us selfless guidance and help, and never tired of helping us to revise and improve the paper.

Secondly, we would like to thank the scholars involved in this paper. This paper cites the research literature of several scholars. Without the help and inspiration of the research results of each scholar, it will be difficult for us to complete the writing of this paper.

\section{References}

1. Zhang Le, Cao Jing. China's Agricultural Total Factor Productivity Growth: the introduction of configuration efficiency change - an empirical analysis based on stochastic frontier production function method $[\mathrm{J}]$. Chinese Rural Economy,2013(03):4-15.

2. J.John Whalley, Lijing Zhu. The Impact of China's Economic Reforms on Agricultural Productivity Growth [J].The Journal of Political Economy, 1989, (97).

3. Guanzhong, James, Wen. Total Factor Productivity Change in China's Farming Sector: 1952-1989[J]. Economic Development \& Cultural Change, 1993.

4. Songqing Jin, Jikun Huang, Ruifa Hu, Scott Rozelle.The Creation and Spread of Technology and Total Factor Productivity in China 's Agriculture [J]. American Journal of Agricultural Economics, 2002, (84).

5. Jiao Yuan. Evaluation Research of Agricultural Production Efficiency in Shandong Province [J]. China Population Resources and Environment, 2013, 23(12):105 - 110

6. Han Zhenxing, Liu Donghui, Chang Xiangyang. Calculation of Agricultural Production Efficiency and Analysis of Regional Differences in China Based on SFA[J].Jiangsu Sciences, 2018,46(23):388-392.

Agricultural

7. Peng Daiyan, Wu Xiang. A study on China's agricultural technology efficiency and TFP - - A perspective on the changes in the structure of rural labor force [J].Economist 2013(09):68-76.

8. Wang Weihua.Stochastic Frontier Analysis of the Efficiency of Regional Agricultural Technology in China [J].Special Zoom Economy,2015,(2):71-73.

9. Yang Yiwu, Lin Wanlong, Zhang Li. Agricultural technological progress, technical efficiency and food production: empirical analysis from Chinese 
provincial panel data [J]. Journal of Agrotechnical Economics,2017,(5):46-56.

10. Song Zengji, Xu Yeqin, Zhang Zongyi. A DEA Efficiency Analysis of Chinese Agriculture [J]. Journal of Chongqing University (Social Science Edition),2008(03):24-29.

11. Chen Weiping. Productivity Growth technical Progress and Efficiency Change in Chinese Agriculture:1990-2003 [J].China Rural Survey, 2006,(1):18-23,38.

12. Zhen Chunji, Yu Guoxin, Li Xiandong. Difference Analysis of the Impact of Agricultural Insurance on Agricultural Technology Efficiency - GMM Estimation Based on Dynamic Panel Data [J].Jiangsu Agricultural Sciences,2018,46(16):323-328.

13. Wang Jun, Yang Xiuyun The Dynamic Evolution and Convergence Analysis of Agricultural Total Factor Productivity in China Since the Reform and Opening $[\mathrm{J}]$. Statistics \& Information Forum,2019,34(11):59-66.

14. Zhou Pengfei, Xie Li, Wang Yafei. An Analysis of the Changes of Agricultural Total Factor Productivity and Its Driving Factors in China_-An Empirical Investigation Based on DEA-Malmquist Index Method and Two-Step System GMM [J].Lanzhou Academic Journal,2019,(12):170-186.

15. Wang Xiufeng, Zhang Ming. Study on Agricultural Production Efficiency of Guizhou Province Based on DEA Model [J]. Economic Tribune,2019,(11):76-84.

16. Hou Ling, Feng Jihong. Analysis of Chinese Agricultural Production Efficiency based on superefficiency DEA and Malmquist index [J]. Journal of Henan Agricultural University,2019,53(2):316-324

17. Baima Yongzhen. Technical efficiency of Agricultural Production in China and its influencing factors: an empirical analysis based on SFA [J]. Journal of Commercial Economics,2016,(23):172-174.

18. Zhang Yu, Sun Dayan, Hu Zitu. Calculating of Agricultural Production Efficiency in Inner Mongolia Autonomous Region and Research on Influencing Factors $[\mathrm{J}]$. Chinese Agricultural Science Bulletin,2015,31(24):271-276.

19. Koopmas T. An analysis of production as an efficient combination of activities. In: Activity analysis of production and allocation, V01 . 13 of Cowles Commission for Research in Economics[M]. NewYork: John Wiley and Sons Press, 1951.

20. Debreu G . The coefficient of resource utilization[J] .Econometrica, 195I, 19(3):273-292 .

21. Bian Wenlong, Wang Xiangnan. A Literature Review on the Stochastic Frontier Analysis in Panel Data [J]. Statistical Research,2016,33(6):13-20.

22. Meeusen W. van den Broeck J. Efficiency estimation form Cobb-Douglas production function with composed errors $[\mathrm{J}]$. International Economic Review, 1977, 18(2):435- 444.

23. Bauese G, Coelli T. A model for technical inefficiency effects in astochastic frontier production function for panel data[J] . Empirical Economics, 1995, 20(2):325-322. 